\title{
Hospital v. community paediatric experience for trainees in child psychiatry
}

\author{
Sandra Duke
}

The beneitis of paediatric experience towards training in child psychiatry are discussed, with emphasis on the differences between hosplial and community posts. Proposed reforms to training for hospltal doctors are discussed with respect to speciallised training in child psychiatry. It is concluded that future training regulations should allow trainee chlld psychlatists to benefit from training in hospltal and/or community paodiatrics.

A recent article in the Psychiatric Bulletin concluded that "experience in community child health is more relevant than hospital paediatrics to future child and adolescent psychiatrists" (Hill et al, 1992). The experience gained in these posts differs greatly, and I wish to reflect on the specific learning gained from attachments in each one, and to discuss their relevance to child psychiatry. My comments are presented in the hope that they maybe of interest and assistance to doctors working in child psychiatry, who are considering an attachment in a paediatric speciality.

\section{Hospital paediatrics}

My initial experience in paediatrics was in a general paediatric hospital which also provided a regional paediatric referral service. This provided exposure to the full spectrum of childhood illness and the psychological consequences for the child, family and staff.

Patterns of illness in children are different from those seen in adults. Children become ill and get better quickly, often being moribund in the evening and running around the ward the next morning. Children show marked resilience and can recover fully after long periods of unconsciousness. For example, young victims of road traffic accidents can be unconscious for several weeks and still make a full recovery.

Life-threatening illness in children often occurs suddenly and requires rapid medical response; in these cases skill is needed to communicate with, and treat, the ill child while at the same time counselling parents who are often in a state of shock, with the awareness that time is all-important. It is a challenge to form and maintain a trusting relationship with a child while administering investigations or treatments which are often painful.

The effect of illness or death of a child is much more intense than the death of an elderly patient and involves parents, siblings and staff. Children identify with other patients suffering from similar illness; for example when an adolescent patient with cystic fibrosis died, other children on the ward were confronted with their own mortality. and required support to address these difficult issues.

Illness behaviour was easily observed. Peer group modelling resulted in increasing antisocial behaviour in 5 to 9 year-old-boys in traction for several months for treatment of fractured femurs. Institutionalisation was apparent in children with chronic illness requiring frequent admissions.

It is at times difficult for all parties to maintain the perspective of the child being only one member of the family, and to address the needs of the other family members when that child is seriously ill. This becomes a problem when dealing with chronic or recurring illness.

Working in hospital gives insight into the clinical side of medicine, for example, how a special care baby unit or children's intensive care unit runs and also an understanding of the reasoning behind procedures that might otherwise appear irrational.

\section{Community paediatrics}

Working in community paediatrics provided a very different experience, with the emphasis on dealing with healthy children. My experience included working in a baby clinic; providing immunisation cover and screening well children; and there was a statutory obligation to provide health screening in schools. There was little contact with children who were physically unwell.

Parents used clinics as a drop-in centre for minor problems or anxieties and advice on 
childhood development and behaviour. Clinical medical officers did not issue prescriptions, and mothers quickly learned to visit their GP if their child required medication.

Working in community paediatrics provided the opportunity to become proficient in examination and feel at ease with young children. This was particularly necessary as testing often required the child's full cooperation. Examining groups of children at the same age gives a perspective of normal development against which to compare referrals to child psychiatry.

Responsibilities also included assessing children in school, frequently seeing ten children of the same age to assess their development in one morning. The service provided yearly medicals for children with known medical problems to assess any impact this may have on their schooling and to ensure that they were functioning and participating at their maximum level in school. I also gained experience in the initial investigation of suspected physical or sexual abuse.

Dealing with children who had learning difficulties included screening for physical causes and associated handicaps such as visual or hearing defects, or undiagnosed epilepsy. Following this, there was contact with other agencies involved, such as support teachers, head teachers, educational social work and educational psychology, and this gave me an indication of the roles and responsibilities of each professional.

\section{Conclusions}

There is no doubt that the benefit gained from a training post depends on personal aims; a prior awareness of the potential learning benefits can help in choosing appropriate attachments and obtaining the maximum benefit from it. Obviously in hospital and community paediatrics the primary emphasis is different, but experience and insights relevant to child psychiatry can be gained from each one. However, what is gained will depend on previous experience and learning.

In hospital paediatrics, exposure to a large number of children with physical illness increases awareness of the patterns and course of childhood illness, allowing observation of the effects of serious illness on children, parents, siblings, other patients and staff. This engenders a sense of competence when discussing physical illness with parents and paediatricians and may improve communication. Chronic illness in children often has physical, psychological and social components which all merit attention in their own right.

In community paediatrics, the opportunity to screen a large number of healthy children provides a quick and effective means of learning normal developmental milestones. It also provides experience in dealing with minor behavioural problems which would rarely be referred to child psychiatry unless there were other contributing or contextual factors. Community paediatrics increases one's knowledge of schooling systems and available community supports. It also gives some insight into the variations in levels of acceptable behaviour between schools, and between teachers in the same school.

As more GPs are providing child health survelllance the role of community paediatricians is changing; nonetheless experience in community paediatrics remains relevant to day-to-day work in child psychiatry. Working only within child psychiatry, the same perspective and experience may be gained, over a period of time; there is, however, little experience in diagnosing or treating physical illness and hospital paediatrics provides this training opportunity.

The implications for training of the NHS reforms and the Calman Report are not yet known. The Calman Report (DoH, 1993) recommends that the arrangements for the first phase of specialist training must provide sufficient flexdbility to enable a training doctor to make an initial commitment to a broad range of specialities. In response, the President of the Royal College of Psychiatrists (Caldicott, 1993) stated that this should be welcomed by the College, if it will lead to greater flexblility in the recognition of other parts of medicine undertaken by the would-be specialist. It is hoped that future revisions of training regulations will allow trainees in child psychiatry to include paediatric experience as approved training experience.

Experience in both hospital and community paediatrics is relevant to training in child and adolescent psychiatry. It is essential to decide on the experience which one hopes to gain from a paediatric attachment and examine posts critically to be sure they are likely to provide that experience.

\section{References}

Caldicott, F. (1993) Response to the Chief Medical Officer's Report on Specialist Training: Hospital Doctors: training for the future. Psychiatric Bulletin, 17, 577-579.

DEPARTMENT OF HEALTH (1993) Hospital Doctors: training for the future. The Report of the Working Group on Specialist Medical Training. (Calman Report). London: HMSO.

HILl, P., DAWkins, J., Griffiths, M.A. \& TALBOT, R. (1992) Experience in community child health as part of training in child and adolescent psychiatry. Psychiatric Bulletin. 16, 355-356.

Sandra Duke, Senior Registrar, in Child and Family Psychiatry, Dudhope House, 15 Dudhope Terrace, Dundee DD3 6HH 